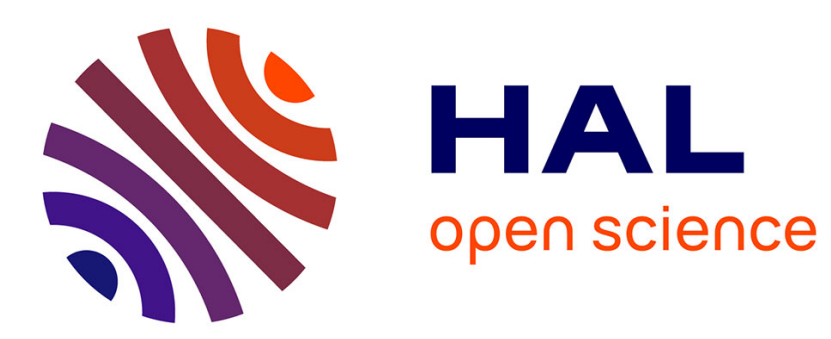

\title{
Spatio-temporal patterns of Chaos in the Atlantic Overturning Circulation
}

\author{
Q. Jamet, W. K Dewar, N. Wienders, B. Deremble
}

\section{To cite this version:}

Q. Jamet, W. K Dewar, N. Wienders, B. Deremble. Spatio-temporal patterns of Chaos in the Atlantic Overturning Circulation. Geophysical Research Letters, 2019, 46 (13), pp.7509-7517. 10.1029/2019GL082552 . hal-02410296

\section{HAL Id: hal-02410296 \\ https://hal.science/hal-02410296}

Submitted on 13 Dec 2019

HAL is a multi-disciplinary open access archive for the deposit and dissemination of scientific research documents, whether they are published or not. The documents may come from teaching and research institutions in France or abroad, or from public or private research centers.
L'archive ouverte pluridisciplinaire HAL, est destinée au dépôt et à la diffusion de documents scientifiques de niveau recherche, publiés ou non, émanant des établissements d'enseignement et de recherche français ou étrangers, des laboratoires publics ou privés. 


\title{
Spatio-temporal patterns of Chaos in the Atlantic Overturning Circulation
}

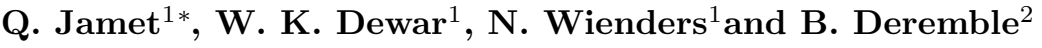 \\ ${ }^{1}$ Department of Earth, Ocean and Atmospheric Science, the Florida State University, Tallahassee, Florida \\ ${ }^{2}$ Laboratoire de Météorologie Dynamique, Paris, France

\section{Key Points:} \\ - We highlight the existence of a basin scale intrinsic mode of AMOC variability shar- \\ ing similarities with the atmospherically forced mode \\ - The RAPID-MOCHA-WBTS array is found to be part of this basin scale mode; \\ $50 \%$ of its interannual variability is ascribed as intrinsic \\ - Our results provide an estimation of the quantitative accuracy of the overturn- \\ ing variability within eddy-resolving ocean models
}

*The Florida State University, 117 N Woodward Avenue, Tallahassee, FL 32306-4320.

Corresponding author: Quentin Jamet, qjamet@fsu.edu 


\section{Abstract}

Examining an ensemble of high-resolution $\left(1 / 12^{\circ}\right)$ North Atlantic ocean simulations, we provide new insights into the partitioning of the Atlantic Meridional Overturning Circulation (AMOC) variability between forced and intrinsic at low-frequency (2-30 years). We highlight the existence of a basin scale intrinsic mode that shares similarities with the atmospherically forced signal. The RAPID-MOCHA-WBTS array is found to be part of this mode, such that we ascribe about $0.9 \mathrm{~Sv}$ (50\% in our configuration) of its interannual variability as intrinsic. At decadal time scales, intrinsic variability is rather small $(\sim 0.2 \mathrm{~Sv})$ compared to the recently observed 2-3 Sv AMOC downturn. This downturn is thus unlikely to be induced by locally generated intrinsic ocean dynamics. We interpret this intrinsic variability as 'chaotic', i.e. somewhat unpredictable, providing an estimation of the quantitative accuracy of AMOC variability within eddy-resolving numerical models.

\section{Introduction}

The Atlantic Meridional Overturning Circulation (AMOC) is an important oceanic component of the climate system, placing a premium on understanding its variability. It affects regional and global climate by modulating oceanic surface temperatures in the North Atlantic (Caesar et al., 2018; Knight et al., 2005; McCarthy et al., 2015), impacting precipitation over Europe (Sutton et al., 2012) and North Africa (Zhang et al., 2006) and influencing hurricane activity in North America (Goldenberg et al., 2001). The mechanisms driving AMOC variability remain however debated mostly due to the large spread in the simulated spatio-temporal patterns between models (Buckley et al., 2016), and due to the difficulties in validating numerical results against sparse and too short observational time series.

The atmosphere is thought to drive a significant portion of AMOC variability at various time scales, such that increasing greenhouse gases are expected to induce a decline of the AMOC (Caesar et al., 2018; Kirtman et al., 2013; Saba et al., 2016). Recent observations suggest that this decline is underway (Smeed et al., 2018). The link between the observed decline and the simulated response to increased greenhouse gases remains unclear however, with observed patterns of surface ocean metrics associated with the observed AMOC decline that resemble those found in climate models (Smeed et al., 2018), but with a much larger amplitude than the simulated long-term forced trend (Smeed et 
al., 2014). Aside from surface forcing, the ocean also develops its own intrinsic variability through meso-scale turbulence (Penduff et al., 2011; Sérazin et al., 2015), so the AMOC strength does not only depend on the atmosphere. The contribution of such intrinsically driven ocean dynamics for the low-frequency AMOC variability has been recently underscored (Grégorio et al., 2015; Leroux et al., 2018), but our understanding of such processes is rather limited. This study sheds more light on such a contribution, and discusses implications for the interpretation of observational data set such as the RAPID-MOCHAWBTS program.

To describe this variability, we use here an ensemble of numerical simulations of the North Atlantic. As we shall see, we have tailored this ensemble to separate the AMOC variability into two contributions: the intrinsic (locally generated) variability and the atmospherically forced variability. We use a high resolution $\left(1 / 12^{\circ}\right)$, regional $\left(20^{\circ} \mathrm{S}\right.$ to $\left.55^{\circ} \mathrm{N}\right)$ North Atlantic configuration to produce a 24-member ensemble consisting of 50-year long members, spanning the period 1963-2012. Each ensemble member corresponds to the same model configuration (external forcing and open boundary conditions). The only difference between the members of the ensemble is the initial condition. We provide a full description of the model in Section 2. In Section 3, we quantify the contribution of the internal ocean dynamics for the total low-frequency AMOC variability, and highlight the existence of a basin scale mode of intrinsic low-frequency AMOC variability. We propose a link between these results and observations at $26.5^{\circ} \mathrm{N}$ provided by the RAPID-MOCHAWBTS program (McCarthy et al., 2015) in Section 4. We conclude and discuss the results in Section 5.

\section{Model and Methods}

The 24-members ensemble simulation is performed with a regional configuration of the Massachusetts Institute of Technology General Circulation Model (MITgcm, Marshall et al., 1997). The North Atlantic domain extends from $20^{\circ} \mathrm{S}$ to $55^{\circ} \mathrm{N}$. The horizontal resolution is $1 / 12^{\circ}$ to resolve oceanic meso-scale turbulence, and 46 layers are used on the vertical, ranging from $6 \mathrm{~m}$ at the surface to $250 \mathrm{~m}$ at depth. Water masses that enter or leave the domain through the northern and the southern boundaries of the domain, as well as at the Strait of Gibraltar, are represented through the use of open boundary conditions derived from the 55 -year long $1 / 12^{\circ}$ horizontal resolution ocean-only global configuration ORCA12.L46-MJM88 (Molines et al., 2014; Sérazin et al., 2015), spatially 
interpolated on our model grid. At the surface, the ocean model is coupled to an atmospheric boundary layer model (CheapAML, Deremble et al., 2013). This approach is used to better represent air-sea exchanges, and to avoid the suppression of surface ocean dynamics caused by a prescribed atmosphere with an infinite heat capacity. When using CheapAML, atmospheric surface temperature and relative humidity respond to ocean surface structures by exchanges computed according to the COARE3 (Fairall et al., 2003) flux formula, but are strongly restored toward prescribed values over land. The reanalysis products used in CheapAML originate from the Drakkar forcing set (DFS4.4, Brodeau et al., 2010; Dussin et al., 2016), consistent with the atmospheric forcing employed in the ORCA12.L46-MJM88 global simulation used to derive the open boundary conditions. The configuration is integrated forward in time for 50 years over the period 1963-2012 with a 24-members ensemble strategy. Initial conditions are constructed with 1-year long simulations initialized from 24 alternative days. The 24 oceanic states at the end of these 1-year long simulations, which reflect the growth of small, dynamically consistent perturbations, were used to initialize the 24 ensemble members. Further details on the configuration, the initial conditions, and the simulated North Atlantic oceanic mean state are provided within the Supporting Information section.

To assess the low-frequency intrinsic AMOC variability, we compute an overturning streamfunction by first zonally integrating the modeled meridional velocities across the North Atlantic, and then vertically from the bottom toward the surface in depth coordinates. We later remove trends and frequencies lower than 50 years in each ensemble member, estimated with a nonparametric locally estimated scatterplot smoothing (LOESS, Cleveland et al., 1988) operator. We compute a climatological annual cycle from the 50year ensemble mean, and then remove this annual cycle from each member. Finally, the residuals are low-pass filtered with a 1-year cut-off period to remove the overwhelmingly large, daily to weekly variability due to atmospheric forcing. This filtering procedure isolates the ocean variability in the 2 to 30 years time bands (cf. Supporting Information).

We use a statistical approach to separate the intrinsically generated from the externally forced variabilities in our ensemble. We first compute an ensemble mean (50 years long time series) by averaging the oceanic state simulated by the 24 members. This time series represents the signal that is common to all members, and is assumed to originate from the external forcing, either from the surface or through the open boundaries. We interpret the ensemble mean as the forced signal, and define its temporal variance $\sigma_{F}^{2}$ 
following Leroux et al. (2018):

$$
\sigma_{F}^{2}=\frac{1}{T} \sum_{t=1}^{T}\left[\left\langle f_{i}(t)\right\rangle-\overline{\left\langle f_{i}(t)\right\rangle}\right]^{2},
$$

with $T$ the length of the 50 -year long simulations, $<.>$ the ensemble mean operator and $\bar{x}$ the time mean operator. Since only initial conditions differ between each realization, the residual of each member with respect to the ensemble mean is, by construction, due to ocean dynamics sensitive to the initial conditions. We interpreted this residual signal as the intrinsic variability, and define its variance $\sigma_{I}^{2}$ following Leroux et al. (2018):

$$
\sigma_{I}^{2}=\overline{\frac{1}{N} \sum_{i=1}^{N}\left[f_{i}(t)-\left\langle f_{i}(t)\right\rangle\right]^{2}},
$$

with $N=24$ the number of members, $i=1, . ., N$ the member number. The total variance is simply defined as the sum of the intrinsic and the forced variance $\sigma_{T}^{2}=\sigma_{I}^{2}+$ $\sigma_{F}^{2}$.

\section{The intrinsic AMOC variability}

We plot in Fig. 1 the intrinsic-to-total AMOC variance ratio $R=\frac{\sigma_{I}^{2}}{\sigma_{T}^{2}}$ in latitudedepth space. This provides a measure of the relative contribution of ocean internal dynamics for the total AMOC variance at interannual-to-decadal time scales. Intrinsic AMOC variability is routinely $40 \%$, and exceeds $60 \%$ in the deep North Atlantic. The high values at depth reflect the faster decrease of the forced variability compared to the intrinsic component (cf Fig. S5). Below $5000 \mathrm{~m}$, although intrinsic variance dominates, both variabilities are weak, making the interpretation from the ratio less significant. Surface ratios are typically smaller, reflecting an increasing control of the AMOC by the atmosphere, although ratios of $30 \%$ are common. R exceeds $50 \%$ at 400 meters near $38^{\circ} \mathrm{N}$ where the Gulf Stream separates from the east coast of the United States, highlighting the strong meso-scale contribution to AMOC variability. Our estimates of the intrinsic-to-total ratio are somewhat larger than earlier studies for this region, but these were conducted with either a different method (Grégorio et al., 2015), or at coarser resolution (Leroux et al., 2018), and with a different air-sea exchange strategy. At $26.5^{\circ} \mathrm{N}, \mathrm{R}$ exceeds $30 \%$ as shallow as 500 meters, and increases near the bottom. Intrinsically driven versus forced AMOC variability at that location is further discussed in Section 4 .

We now extract the leading modes of forced and intrinsic AMOC variability in the latitude-depth space and compare their respective spatio-temporal patterns. The first 
Empirical Orthogonal Function (EOF) of the ensemble mean AMOC is shown on the top left panel of Fig. 2. It explains roughly $40 \%$ of the total forced AMOC variance, and is characterized by a broad positive signal from about $10^{\circ} \mathrm{S}$ to roughly $45^{\circ} \mathrm{N}$, and negative signal elsewhere. This pattern strongly resembles the delayed response of the AMOC to the North Atlantic Oscillation (NAO) usually identified in climate and ocean models (Deshayes et al., 2008; Eden \& Jung, 2001; Eden \& Willebrand, 2001; Gastineau et al., 2012), and its associated Principal Component (PC, bottom left panel) peaks in the 2-3 and 6-8 year frequency bands typical of the NAO spectrum (Czaja et al., 2001; Reintges et al., 2017). Furthermore, additional sensitivity experiments to surface forcing (not detailed in this study) reveal that this mode of variability is not reproduced if the ocean is driven by yearly repeating atmospheric conditions. We thus interpret this first EOF as the signature of a local, atmospherically forced AMOC variability.

To extract the leading mode of intrinsic AMOC variability, we perform a Principal Component Analyses for each ensemble residual and average the results (Fig. 2). We first note that the 10 first EOFs explain about $75 \%$ of the total intrinsic AMOC variance, while this number reaches more than $90 \%$ in the case of the forced signal. Such difference is indicative of a less organized intrinsic variability. The variance explained by the first intrinsic EOF is relatively high $(\sim 30 \%)$, and the averaging procedure highlights the emergence of a large scale mode of variability extending from $10^{\circ} \mathrm{S}$ to about $35^{\circ} \mathrm{N}$ with a maximum of about $1 \mathrm{~Sv}\left(1 \mathrm{~Sv}=10^{6} \mathrm{~m}^{3} \mathrm{~s}^{-1}\right)$ around $20^{\circ} \mathrm{N}$ and $2000 \mathrm{~m}$ depth. This pattern exhibits spatial similarities with the atmospherically forced mode discussed earlier. Notable differences arise however in their spectral properties, where both intrinsic and forced leading modes peak (locally) at interannual time scales. The intrinsic PSD decreases monotonically at lower frequencies whereas the forced mode dominates at long time scales. This suggest that in the future generation of climate models with eddy resolving ocean models, projections of future changes in the North Atlantic overturning would be somewhat limited at interannual timescales, but might benefit from better predictive skills at decadal and longer timescales, consistent with the theoretical investigation of Sévellec et al. (2018). Although the dynamical origin of this large scale intrinsic mode of AMOC variability remains to be investigated in depth, the physical processes responsible for their emergence could involve spatio-temporal inverse cascade of kinetic energy (Arbic et al., 2014, 2012). Such a process has been recently identified as a driver 
for the low frequency intrinsic variability of sea level anomaly (Sérazin et al., 2018), and is thus likely to contribute to intrinsic AMOC variability as well.

Finally, note that, although intrinsic variability controls more than $50 \%$ of the total variability in the Gulf Stream (Fig. 1), this region does not appear to be part of the leading modes of intrinsic AMOC variability as computed here. We suspect this is due to the meso-scale dynamics of this region, and Gulf Stream instabilities, which do not yield coherent basin scale patterns of variability, but might impact the jet behavior locally close to the coast as proposed earlier by Taguchi et al. (2007) and Taguchi et al. (2010) for the Kurushio Extension. As a result, although some signals are found in the second (Fig. S8) and subsequent EOFs for each individual member, they take place at slightly different locations such that averaging strongly damp their signature (Fig. 2, middle right panel). In other word, such modes of variability are member-dependent, and not considered here.

\section{A focus on RAPID observations}

We examine our ensemble-based results in the context of observations and discuss implications for the interpretation of these. The RAPID-MOCHA-WBTS program (McCarthy et al., 2015) refers to a large, multi-national effort to monitor the strength of the AMOC along $26.5^{\circ} \mathrm{N}$. We have computed numerical equivalents of the observed AMOC by integrating net model northward transport across the North Atlantic, from Florida to the west coast of Africa, and from bottom up (cf Supporting Information). Left panel of Fig. 3 compares the time evolution of the AMOC northward transport anomalies at 1200 meters, the maximum AMOC (Fig. 1), as measured by the RAPID array (red line) against that simulated by our 24 ensemble members (thin gray lines). We first note that our simulated AMOCs tend to underestimate the observations at the beginning of the record and overestimate them toward the end. This mismatch is associated with the observed weakening (2-3 Sv) AMOC trend from 2004 to 2012, a decrease argued to be due to a change in mid-ocean geostrophic (Smeed et al., 2014). Our simulations do not capture this over the 2005-2011 time-frame, and we do not either obtain intrinsic low-frequency variability this large. The PSD of the second intrinsic mode of variability is found to dominate over the forced component at decadal time scale (Fig. 2, bottom right panel). However, this second EOF explains only $10 \%$ of the intrinsic variance, such that it is likely to contribute only for $\sim 0.2 \mathrm{~Sv}$ to the total AMOC variability. We thus conclude that the 
observed 2-3 Sv AMOC transport downturn between 2004 and 2012 cannot be explained as local intrinsic variability at leading order. Additionally, we shall mention that we have conducted sensitivity experiments on the choice of open boundary conditions by comparing companion ensembles driven by either fully varying or yearly repeating conditions. Their preliminary analysis reveals that the decadal AMOC variability at $26.5^{\circ} \mathrm{N}$ is mostly driven by remote signals entering the domain through boundaries. We thus suspect our simulations do not capture the 2-3 AMOC downturn between 2004 and 2012, as observed by RAPID, in response to a too weak signal imposed at the boundaries. Further investigations of such remote signals are underway and will be reported in upcoming communications.

The level of agreement between the observed and ensemble mean AMOC transports (Fig. 3, black line) remains however fairly high (correlation $r=0.8$ ), with predominant near-seasonal fluctuations of $\sim \mathrm{O}(1 \mathrm{~Sv})$. The pronounced weakening $(\sim 3 \mathrm{~Sv})$ of the AMOC over the period 2009/2010 interpreted by others as due to atmospheric forcing (Roberts et al., 2013) is for instance well reproduced by all members. Each exhibits peculiarities however, such that AMOC variability is also member-dependent, highlighting the presence of an intrinsic variability at that location. At $26.5^{\circ} \mathrm{N}$, our estimate of the intrinsicto-total variance ratio $\mathrm{R}$ is $30-40 \%$ at 1200 meters, the maximum AMOC (Fig. 1). The power spectral analysis of the simulated time series (Fig. 3, right panel) reveals that intrinsic ocean dynamics contributes about $50 \%$ at interannual time scales but is much weaker at decadal time scales. In terms of volume transport, these variabilities are associated with an AMOC standard deviation of about $0.9 \mathrm{~Sv}$ and $0.2 \mathrm{~Sv}$, respectively. Preliminary results emerging from the additional sensitivity experiments aforementioned reveal a weak sensitivity of this intrinsic variability to changes in the spectral content of the forced component. This suggests a relatively strong robustness of the intrinsic mode of variability discussed in the present study. This will be further discussed in an upcoming publication, along with the detailed description of the sensitivity experiments.

The time scale separation between forced and intrinsic variability observed at RAPID location echoes the difference in spectral properties between the leading modes of forced and intrinsic AMOC variability discussed earlier (Section 3). To shed light on such a potential connection between the temporal variability at $26.5^{\circ} \mathrm{N}$ and the leading mode of AMOC variability, we have regressed the AMOC signals in the latitude-depth space onto the time series at $26.5^{\circ} \mathrm{N}$ (Fig. 4). The forced ocean response at the RAPID location is 
associated with positively correlated anomalies from $10^{\circ} \mathrm{S}$ to $45^{\circ} \mathrm{N}$ intensified between 1000 and 2000 meters, and negatively correlated anomalies elsewhere. This spatial pattern strongly resembles the first EOF of the forced signal (Fig. 2), with a correlation factor of $r=0.81$ between associated time series. Similarly, the regression pattern for the intrinsic AMOC variability at $26.5^{\circ} \mathrm{N}$ resembles the first EOF of the intrinsic signal (Fig. 2), with positively correlated anomalies from $10^{\circ} \mathrm{S}$ to about $35^{\circ} \mathrm{N}$ (Fig. 4, right panel), and a correlation factor of $r=0.68$ between associated time series. The similarities between regression maps and EOFs strongly suggest that the temporal variability at $26.5^{\circ} \mathrm{N}$ is part of a spatially distributed North Atlantic structure, with both intrinsic and forced origins that mostly differ by their spectral properties.

\section{Conclusion}

We have discussed here the results of an ensemble-based examination of the Atlantic Meridional Overturning Circulation (AMOC) variability at low-frequency (2-30 years) in a high resolution $\left(\frac{1}{12}^{\circ}\right)$ regional $\left(20^{\circ} \mathrm{S}-55^{\circ} \mathrm{N}\right)$ configuration of the MITgcm, and we have identified the dominant spatio-temporal patterns of variability. Our results suggest that, when meso-scale ocean eddies are resolved, a significant fraction of the AMOC variability is sensitive to oceanic initial conditions. This provides a concrete manifestation that the ocean is a chaotic system, which is likely to add an extra source of variability in the next generation of climate models as opposed to the current climate models with non-eddy-resolving ocean modulus (Germe et al., 2017). In our regional configuration, the contribution of such a chaos is found to exceed $50 \%$ in the Gulf Stream region, and to 30-40\% at the RAPID location. By extracting the leading modes of variability through Principal Component Analysis, we have revealed the presence of a basin scale mode of intrinsic AMOC variability in the North Atlantic. The variability of this intrinsic mode peaks at interannual time scales, and its spatial pattern resembles the mode of AMOC variability locally forced by the atmosphere. This resemblance makes the attribution of the interannual AMOC variability as forced or intrinsic from a single, eddyresolving numerical experiment or from observations even more challenging. Our results extend in the latitude-depth space earlier investigations of intrinsically versus forced AMOC variability performed by Grégorio et al. (2015) and Leroux et al. (2018) which were limited to the maximum of the transport over vertical levels. Although strategies differ between studies, similarities in results suggest that the intrinsic mode of AMOC variabil- 
ity identified here is a robust feature of the North Atlantic subtropical gyre dynamics. The structure is coherent with depth and seems to be weakly sensitive to both model construction and the associated changes in the simulated time mean and forced AMOC variability. As suggested by one of the reviewers of this paper, we want to emphasize that our results are limited to intrinsic variability locally generated within the North Atlantic. By construction, any intrinsic variability generated outside our regional configuration is imprinted in the forced component through open boundaries. Thus, for instance the South Atlantic intrinsic mode identified by Leroux et al. (2018) in their global ensemble simulations is contained in our boundary data and therefore common to all ensemble members. Based on their earlier estimates, this mode is likely to contribute to about $0.1 \mathrm{~Sv}$ to the intrinsic AMOC variability in the North Atlantic subtropical gyre.

We compared our model output with the RAPID-MOCHA-WBTS program for which continuous measurements of the AMOC at $26.5^{\circ} \mathrm{N}$ are performed since 2004 (McCarthy et al., 2015). At low-frequency, the dominant observed trend in the left panel of Fig. 3 is the 2-3 Sv AMOC transport downturn interpreted by Smeed et al. (2014) as a result of mid-ocean geostrophic dynamics. Our simulations do not capture this over the 20052011 timeframe. Moreover, we do not obtain intrinsic low-frequency variability this large; our low-frequency fluctuation estimates are more like $\sim 0.2 \mathrm{~Sv}$. The observed downturn can thus not be attributed to local intrinsic variability only, although our estimate remains in the range of long-term AMOC forced trends simulated by climate models (Caesar et al., 2018). However, as pointed out earlier, our results are limited to intrinsic variability of North Atlantic origin. We focus here on one ensemble, but have others where boundary conditions are varying. Their analyses, not detailed here, suggest the downturn originates perhaps in the Labrador (Jackson et al., 2016) or Nordic Seas, with an unknown forced or intrinsic origin.

The simulated and observed signals agree fairly well in the high frequency band, where predominant $\mathrm{AMOC}$ variations of $\sim \mathrm{O}(1 \mathrm{~Sv})$ of the observed signal are consistently captured by the ensemble mean. We have found the leading forced EOF peaks at 2-3 years, and interpret this as atmospherically forced AMOC interannual variability. This is consistent with the previous interpretation of the 2009-2010 event as atmospherically forced (Roberts et al., 2013). We note that all members are not phase locked to the atmosphere because of the intrinsic dynamics of the ocean, with a contribution $\left(\sigma_{I}^{H F}=0.9 \mathrm{~Sv}\right)$ that equals the forced signal at interannual time scales. Equivalently, a significant frac- 
tion ( $50 \%$ in our regional configuration) of the interannual AMOC variability at $26.5^{\circ} \mathrm{N}$ is chaotic, and thus the RAPID timeseries represents only one possible trajectory among many. These results provide a first estimate of the quantitative accuracy of the AMOC within eddy-resolving ocean-only models. Probabilistic estimates as in Chapron et al. (2018) might well represent a useful avenue for further pursuit.

\section{Acknowledgments}

This work has been founded by the NSF award OCE1537304, and benefited from interations with the international CHAOCEAN program lead by Thierry Penduff. Highperformance computing resources on Cheyenne (doi:10.5065/D6RX99HX) have been provided by NCAR's Computational and Information Systems Laboratory, sponsored by the National Science Foundation, under the university large allocations UFSU0011. We also acknowledge Bernard Barnier from l'Institut des Géosciences de l'Environnement (IGE, Grenoble, France) and his collaborators for providing necessary data to force our regional model. The ensemble simulation used in this study is available at http://ocean .fsu.edu/ qjamet/share/data/chaos_amoc_GRL2019/.

\section{References}

Arbic, B. K., Müller, M., Richman, J. G., Shriver, J. F., Morten, A. J., Scott, R. B., ... Penduff, T. (2014). Geostrophic turbulence in the frequency-wavenumber domain: Eddy-driven low-frequency variability. J. Phys. Oceanogr., 44(8), 2050-2069.

Arbic, B. K., Scott, R. B., Flierl, G. R., Morten, A. J., Richman, J. G., \& Shriver, J. F. (2012). Nonlinear cascades of surface oceanic geostrophic kinetic energy in the frequency domain. J. Phys. Oceanogr., 42(9), 1577-1600.

Brodeau, L., Barnier, B., Treguier, A.-M., Penduff, T., \& Gulev, S. (2010). $\quad$ An ERA40-based atmospheric forcing for global ocean circulation models. Ocean Modelling, 31(3-4), 88-104.

Buckley, M. W., \& Marshall, J. (2016). Observations, inferences, and mechanisms of the Atlantic Meridional Overturning Circulation: A review. Reviews of Geophysics, 54(1), 5-63.

Caesar, L., Rahmstorf, S., Robinson, A., Feulner, G., \& Saba, V. (2018). Observed fingerprint of a weakening Atlantic Ocean overturning circulation. Nature, 
556(7700), 191.

Chapron, B., Dérian, P., Mémin, E., \& Resseguier, V. (2018). Large-scale flows under location uncertainty: a consistent stochastic framework. Quarterly Journal of the Royal Meteorological Society, 144 (710), 251-260.

Cleveland, W. S., \& Devlin, S. J. (1988). Locally weighted regression: an approach to regression analysis by local fitting. Journal of the American statistical association, 83(403), 596-610.

Colin de Verdière, A., \& Huck, T. (1999). Baroclinic instability: An oceanic wavemaker for interdecadal variability. J. Phys. Oceanogr., 29(5), 893-910.

Czaja, A., \& Marshall, J. (2001). Observations of atmosphere-ocean coupling in the North Atlantic. Quarterly Journal of the Royal Meteorological Society, 127(576), 1893-1916.

Deremble, B., Wienders, N., \& Dewar, W. (2013). Cheapaml: A simple, atmospheric boundary layer model for use in ocean-only model calculations. Mon. Wea. Rev., $141(2), 809-821$.

Deser, C., Phillips, A., Bourdette, V., \& Teng, H. (2012). Uncertainty in climate change projections: the role of internal variability. Climate dynamics, 38(3-4), $527-546$.

Deshayes, J., \& Frankignoul, C. (2008). Simulated variability of the circulation in the North Atlantic from 1953 to 2003. J. Clim., 21(19), 4919-4933.

Dussin, R., Barnier, B., Brodeau, L., \& Molines, J. (2016). The making of the drakkar forcing set dfs5. DRAKKAR/MyOcean Rep. 01-04, 16 .

Eden, C., \& Jung, T. (2001). North Atlantic interdecadal variability: Oceanic response to the North Atlantic Oscillation (1865-1997). J. Clim., 14, 676-691.

Eden, C., \& Willebrand, J. (2001). Mechanism of interannual to decadal variability of the north atlantic circulation. J. Clim., 14(10), 2266-2280.

Fairall, C., Bradley, E. F., Hare, J., Grachev, A., \& Edson, J. (2003). Bulk parameterization of air-sea fluxes: Updates and verification for the coare algorithm. $J$ Clim., 16(4), 571-591.

Gastineau, G., \& Frankignoul, C. (2012). Cold-season atmospheric response to the natural variability of the Atlantic meridional overturning circulation. Clim. Dyn., 39(1-2), 37-57.

Germe, A., Sévellec, F., Mignot, J., Swingedouw, D., \& Nguyen, S. (2017). On the 
robustness of near term climate predictability regarding initial state uncertainties. Climate dynamics, 48(1-2), 353-366.

Goldenberg, S. B., Landsea, C. W., Mestas-Nuñez, A. M., \& Gray, W. M.

$(2001)$ The recent increase in atlantic hurricane activity: Causes and implications. Science, 293(5529), 474-479.

Grégorio, S., Penduff, T., Sérazin, G., Molines, J.-M., Barnier, B., \& Hirschi, J.

(2015). Intrinsic variability of the atlantic meridional overturning circulation at interannual-to-multidecadal time scales. Journal of Physical Oceanography, 45(7), 1929-1946.

Jackson, L. C., Peterson, K. A., Roberts, C. D., \& Wood, R. A. (2016). Recent slowing of Atlantic overturning circulation as a recovery from earlier strengthening. Nature Geoscience, 9(7), 518.

Huck, T., Colin de Verdière, A., \& Weaver, A. J. (1999). Interdecadal variability of the thermohaline circulation in box-ocean models forced by fixed surface fluxes. J. Phys. Oceanogr., 29(5), 865-892.

Huck, T., \& Vallis, G. K. (2001). Linear stability analysis of three-dimensional thermally-driven ocean circulation: application to interdecadal oscillations. Tellus, 53A, 526-545.

Kirtman, B., Power, S., Adedoyin, A., Boer, G., Bojariu, R., Camilloni, I., ... others (2013). Near-term climate change: projections and predictability.

Knight, J. R., Allan, R. J., Folland, C. K., Vellinga, M., \& Mann, M. E. A signature of persistent natural thermohaline circulation cycles in observed climate. Geophys. Res. Lett., 32(L20708).

Leroux, S., Penduff, T., Bessières, L., Molines, J.-M., Brankart, J.-M., Sérazin, G., ... Terray, L. (2018). Intrinsic and Atmospherically Forced Variability of the AMOC: Insights from a Large-Ensemble Ocean Hindcast. Journal of Climate, $31(3), 1183-1203$.

Lorenz, E. N. (1963). Deterministic nonperiodic flow. Journal of the atmospheric sciences, 20(2), 130-141.

Marshall, J., Adcroft, A., Hill, C., Perelman, L., \& Heisey, C. (1997). $\quad$ A finitevolume, incompressible Navier Stokes model for studies of the ocean on parallel computers. J. Geophys. Res., 102(C3), 5753-5766.

McCarthy, G.D., Smeed, D.A., Johns, W.E., Frajka-Williams, E., Moat, B.I., 
Rayner, D., Baringer,M.O., Meinen, C.S., Collins, J., .. Bryden, H.L. (2015). Measuring the atlantic meridional overturning circulation at $26 \mathrm{n}$. Progress in Oceanography, 130, 91-111.

McCarthy, G. D., Haigh, I. D., Hirschi, J. J.-M., Grist, J. P., \& Smeed, D. A. (2015). Ocean impact on decadal Atlantic climate variability revealed by sea-level observations. Nature, 521(7553), 508-510.

Molines, J., Barnier, B., Penduff, T., Treguier, A., \& Le Sommer, J.

Orca12. 146 climatological and interannual simulations forced with dfs4. 4:

Gjm02 and mjm88. drakkar group experiment rep (Tech. Rep.). GDRI-

DRAKKAR-2014-03-19, 50 pp.[Available online at http://www. drakkar-ocean. eu/publications/reports/orca12_reference_experiments_2014.].

Penduff, T., Juza, M., Barnier, B., Zika, J., Dewar, W. K., Treguier, A.-M., ... Audiffren, N. (2011). Sea level expression of intrinsic and forced ocean variabilities at interannual time scales. J. Clim., $24(21), 5652-5670$.

Reintges, A., Latif, M., \& Park, W. (2017). Sub-decadal North Atlantic Oscillation variability in observations and the Kiel climate model. Climate Dynamics, 48(11-12), 3475-3487.

Roberts, C., Waters, J., Peterson, K., Palmer, M., McCarthy, G., Frajka-Williams, E., ... others (2013). Atmosphere drives recent interannual variability of the Atlantic meridional overturning circulation at 26.5 N. Geophysical Research Letters, 40(19), 5164-5170.

Saba, V. S., Griffies, S. M., Anderson, W. G., Winton, M., Alexander, M. A., Delworth, T. L., ... others (2016). Enhanced warming of the Northwest Atlantic Ocean under climate change. Journal of Geophysical Research: Oceans, $121(1), 118-132$.

Sérazin, G., Penduff, T., Grégorio, S., Barnier, B., Molines, J.-M., \& Terray, L. (2015). Intrinsic variability of sea level from global ocean simulations: Spatiotemporal scales. J. Clim., 28(10), 4279-4292.

Sérazin, G., Penduff, T., Barnier, B., Molines, J.-M., Arbic, B. K., Müller, M., \& Terray, L. (2018). Inverse cascades of kinetic energy as a source of intrinsic variability: A global ogcm study. J. Phys. Oceanogr., 48(6), 1385-1408.

Sévellec, F., Dijkstra, H. A., Drijfhout, S. S., \& Germe, A. (2018). Dynamical attribution of oceanic prediction uncertainty in the North Atlantic: application to 
the design of optimal monitoring systems. Clim. Dyn., 51(4), 1517-1535.

Sévellec, F., \& Fedorov, A. V. (2013). The leading, interdecadal eigenmode of the Atlantic meridional overturning circulation in a realistic ocean model. J. Clim., 26(7), 2160-2183.

Smeed, D., Josey, S., Beaulieu, C., Johns, W., Moat, B., Frajka-Williams, E., ... others (2018). The North Atlantic Ocean is in a state of reduced overturning. Geophysical Research Letters, 45(3), 1527-1533.

Smeed, D., McCarthy, G., Cunningham, S., Frajka-Williams, E., Rayner, D., Johns, W., ,.. others (2014). Observed decline of the atlantic meridional overturning circulation 2004-2012. Ocean Science, 10(1), 29-38.

Sutton, R. T., \& Dong, B. (2012). Atlantic Ocean influence on a shift in European climate in the 1990s. Nature Geoscience, 5(11), 788.

Taguchi, B., Xie, S.-P., Schneider, N., Nonaka, M., Sasaki, H., \& Sasai, Y. (2007). Decadal variability of the kuroshio extension: Observations and an eddyresolving model hindcast. J. Clim., 20(11), 2357-2377.

Taguchi, B., Qiu, B., Nonaka, M., Sasaki, H., Xie, S.-P., \& Schneider, N. (2010). Decadal variability of the kuroshio extension: mesoscale eddies and recirculations. Ocean Dynamics, 60(3), 673-691.

Te Raa, L. A., \& Dijkstra, H. A. (2002). Instability of the thermohaline ocean circulation on interdecadal timescales. J. Phys. Oceanogr., 32(1), 138-160.

Zhang, R., \& Delworth, T. L. (2006). Impact of Atlantic multidecadal oscillations on India/Sahel rainfall and Atlantic hurricanes. Geophysical Research Letters, $33(17)$. 


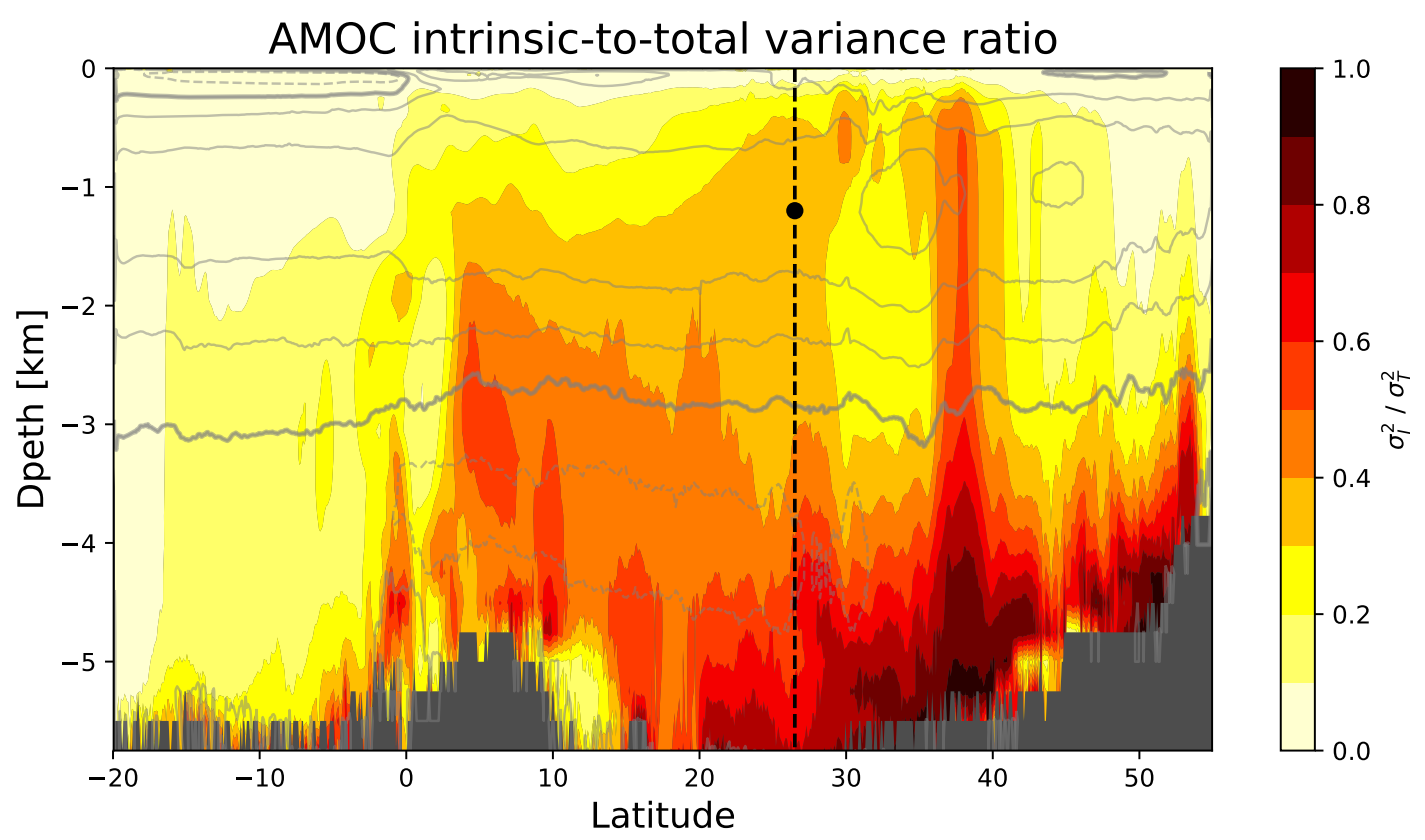

Figure 1. Intrinsic-to-total variance ratio $R=\frac{\sigma_{I}^{2}}{\sigma_{T}^{2}}$ of the simulated interannual-to-decadal AMOC variability. $R$ indicates the fraction of the low-frequency AMOC variability that is driven by the chaotic internal ocean dynamics in the ensemble simulation (color contours every 0.1).

Gray contours indicate the simulated time mean AMOC, with a contour interval of $5 \mathrm{~Sv}(1 \mathrm{~Sv}=$ $10^{6} \mathrm{~m}^{3} \mathrm{~s}^{-1}$ ) and a thick contour for the zero value. The black dashed line represents the location of the RAPID array at $26.5^{\circ} \mathrm{N}$, and the black dot indicates the depth of $1200 \mathrm{~m}$ used in Fig. 3 . 

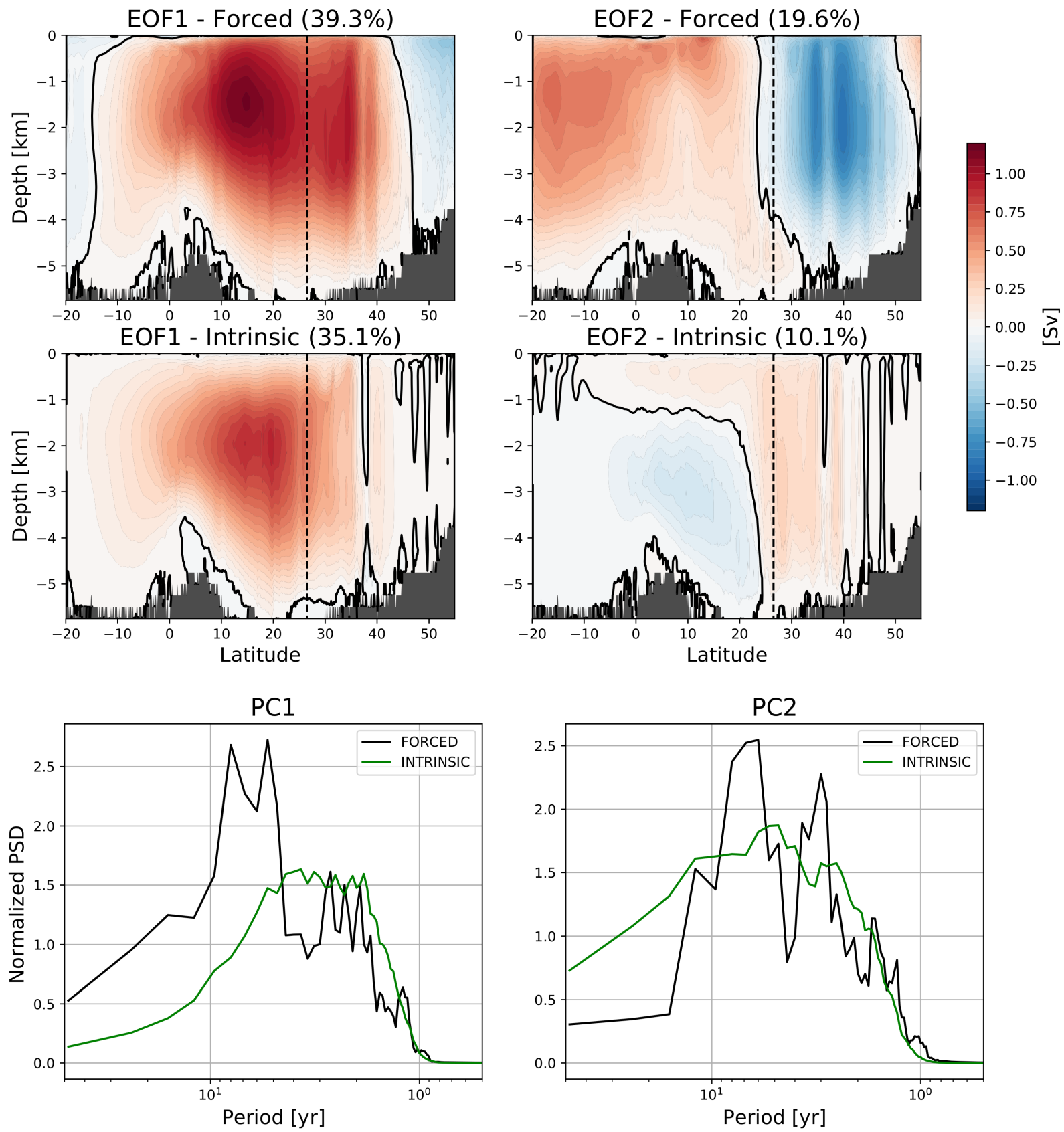

Figure 2. First (left) and second (right) Empirical Orthogonal Functions (EOFs) for the ensemble mean AMOC (top), for the intrinsic AMOC variability (middle), and the Power Spectral Density (PSD) function of the associated Principal Component (PC, bottom). The EOFs have been normalized such that they contain the amplitude in Sv of the explained signal, and the explained variance is shown on top of each panel. For the intrinsic component, the EOF and associated spectra have been computed for each individual member and then averaged together. 

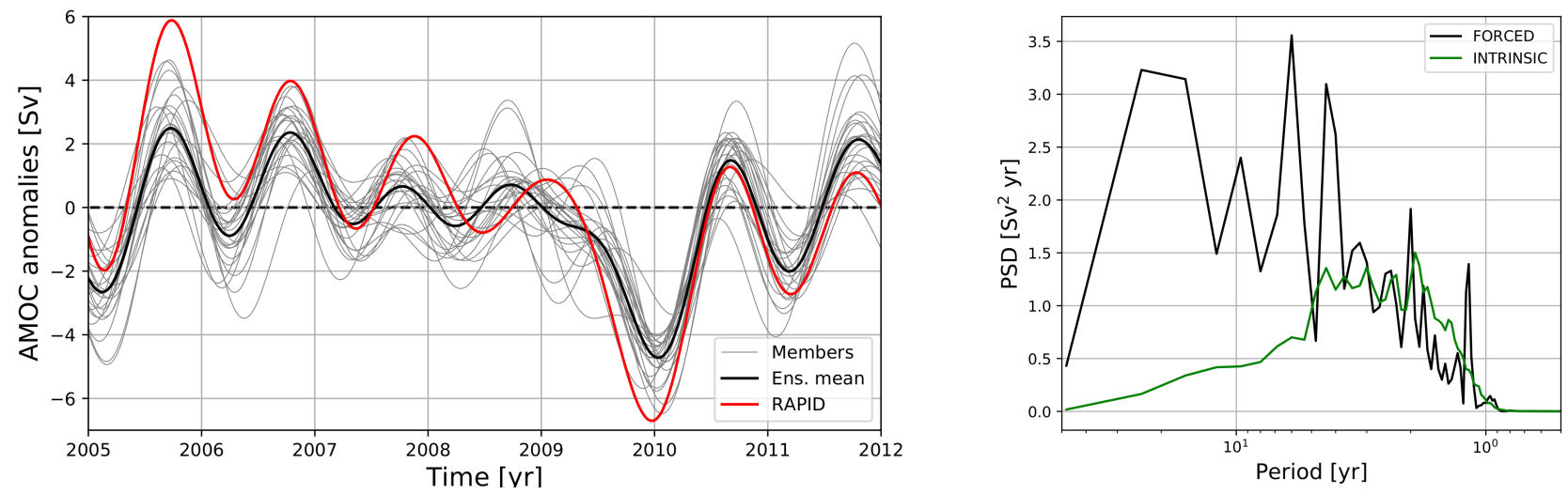

Figure 3. (Left) Time series corresponding to the variations of the northward AMOC transport, the maximum of which occurs around $1200 \mathrm{~m}$ depth in our model. Individual ensemble members (24) are shown in light gray and the ensemble mean in black. The measured AMOC at the same depth appears in red. All data have been low-pass filtered with a cutoff period of 1 year. The first and last years of data have been discarded due to side effects induced by the filtering. (Right) Power Spectral Density (PSD) of the forced (black) and intrinsic (green) component of the simulated AMOC anomalies at $26.5^{\circ} \mathrm{N}$ and $1200 \mathrm{~m}$ for the $50-\mathrm{yr}$ long signal. Data have been high-pass filtered and a seasonal cycle has been removed before the application of the 1-yr low-pass filter (see text for details). The First and last years have been discarded due to side effects induced by the filtering. 

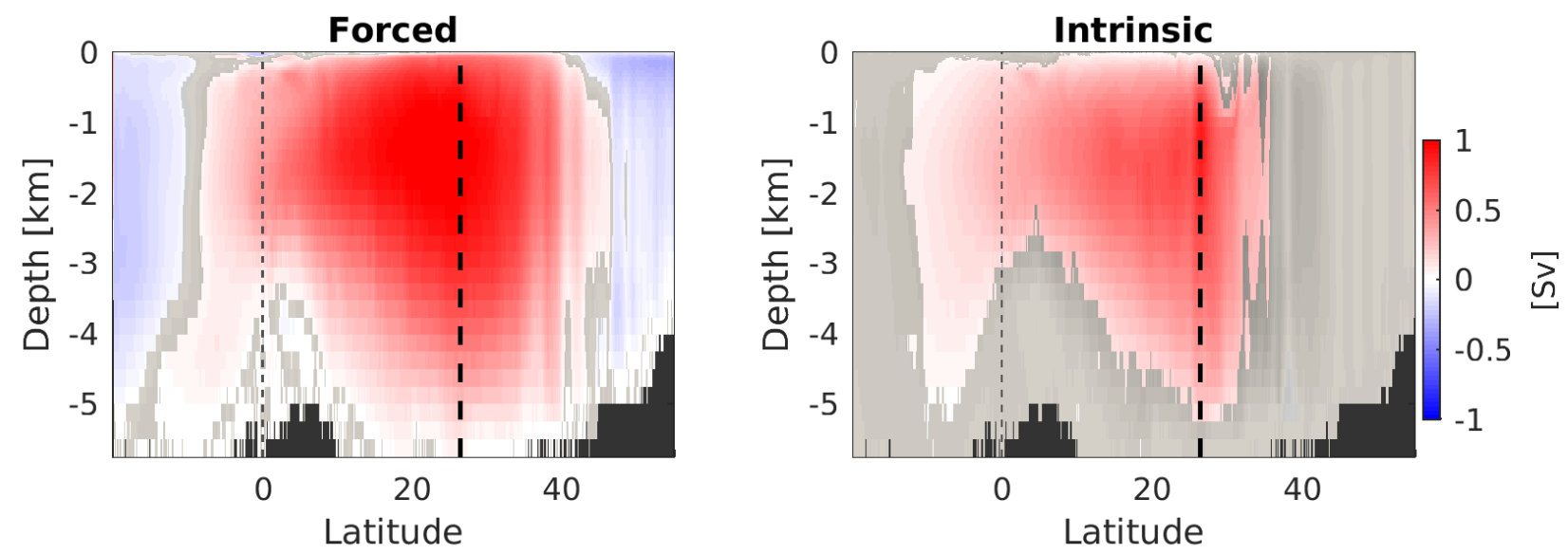

Figure 4. Regressed $\mathrm{AMOC}[\mathrm{Sv}]$ in the latitude-depth space onto the AMOC time series at $26.5^{\circ} \mathrm{N}$ and $1200 \mathrm{~m}$ for the forced (left) and the intrinsic (right) component. Statistical significance has been assessed with a Monte Carlo approach by comparing the regression to that of a randomly scrambled ensemble. We have randomly permuted the AMOC time series by block of 15 days and computed a regression. This process, which aims at removing autocorrelation in the time series, is repeated 100 times. If the original regression is larger than $95 \%$ of the scrambled ensemble regressions, it is considered as statistically significant. Regressions that are not statistically significant are gray shaded. The black dashed line represents the location of the RAPID array at $26.5^{\circ} \mathrm{N}$. 